\title{
Creation of seamless geological map of Japan at the scale of 1:200,000 and its distribution through the web
}

\author{
— For maximum accessibility and utilization of geological information -
}

\author{
Koji Wakita*, Toshie Igawa**, Shinji Takarada** and Yuichiro Fusejima** \\ [Translation from Synthesiology, Vol.1, No.2, p.82-93 (2008)]
}

\begin{abstract}
A seamless geological map with unified legend was created at the scale of 1:200,000 covering the entire Japanese Archipelago. This was accomplished by harmonizing regional geological maps that were compiled in various ages. A research scenario from basic geological research to information technology (IT) for distribution of digital geological maps was designed. Type 2 Basic Research was proposed to distribute the interoperable data set of geological maps, which were transformed from the results of Type 1 Basic Research for geological mapping. Seamless geological mapping was finally proposed as a Full Research program in geological research field.
\end{abstract}

Keywords : Geological map, seamless, web distribution, standardization, GeoSciML, GEO Grid

\section{Introduction}

Geology has two major characteristics: first, it is a basic natural science that investigates natural phenomena on and beneath the earth's surface; second, it is an applied science that explores natural resources in response to social requirements of the times. The first geological map created at the dawn of geology provided us with valuable knowledge and information about natural resources such as oil, coal, iron, and diamond ${ }^{[1]}$. It also introduced use to the mysteries of the underground. Today, geology continues to evolve and is accumulating comprehensive knowledge of the earth system. It also plays an important role as a practical science in many fronts such as natural resources, environment, and disaster prevention. This practical role is emphasized in the subtitle "Earth Science for Society" for the International Year of Planet Earth 2008.

In Japan, numerous geological maps were published at different scales by the Geological Survey of Japan (the predecessor of present Geological Survey of Japan of the AIST) since its establishment in 1882. From the Meiji Era (late nineteenth century) to the reconstruction period after the Second World War, the geological maps were used as basic information for exploring mineral resources that contributed significantly to the development of industries. Presently, they are used as basic information for industrial locations, disaster prevention, and environmental studies. Particularly, the 1:200,000 scale geological maps were compiled and utilized as the most detailed maps covering the entire Japanese Archipelago.

Geological maps, which were compiled by elaborate field survey followed by advanced research, provide the latest geological knowledge for the crustal development of the Japanese Archipelago. These maps contain not only basic information of the underground, but also are the distinguished products of Type 1 Basic Researches that contribute to the construction of knowledge system ${ }^{[2][3]}$.

Geological maps are always compiled based on the latest geological model of the time. Since new geological models emerge with the progress of geology, it often happens that two maps compiled at different periods, even though they are adjacent, may be represented by different geological divisions and/or legend, and the distribution of formations may be discontinuous.

Because of such inconveniences, we are faced with growing need to revise and update these geological maps made at different ages with latest model and knowledge obtained in field surveys. Expanding this operation nationwide will make geological maps more useful and helpful in our society. Likening the situation where current research become outdated and inapplicable as time goes by to the "valley of death" in research, we must promote Type 2 Basic Research to make past accomplishments more valuable and escape this situation. The research of seamless geologic maps aims to recreate valuable geoinformation for society.

This study contributes not only to the development and management of useful geoinformation, but it also develops both Internet deliverable technologies that facilitate wider use of geological maps and standardization of interoperation among different spatial information. We also intend to develop, deliver, and utilize the information through the network in and outside Japan to provide Full Research. Upto-date web delivery technologies can be applied to seamless geological map, to make data compliant to international standards. This is expected to stimulate faster and broader distribution of detailed and precise geoinformation.

* Geoinformation Center, AIST * * Institute of Geology and Geoinformation, AIST Tsukuba Central 7, Tsukuba, Ibaraki 305-8567, Japan * E-mail : koji-wakita@aist.go.jp 
Furthermore, interoperation with other information systems will help establish safer society in terms of infrastructure and disaster prevention.

In this paper, first we present the outline of seamless geological map and its research scenario, which was designed as Type 2 Basic Research in order to actively promote the development of basic intellectual knowledge of Japan. Then we show how to select appropriate knowledge to provide clear and plain geoinformation to the public. Studies of geological maps can be considered as both Type 1 and Type 2 Basic Researches, because they provide various useful geoinformation by integrating broad range of knowledge such as paleontology, structural geology, stratigraphy, and petrology. However, many recent geological maps tend to be thematically specialized, and are published as basic research report with highly advanced research outcomes, stressing the aspect that they are results of Type 1 Basic Researches. In contrast to this recent trend, we shall describe the methodology and features of seamless geological maps as an example of Type 2 Basic Research, which can create great values for society by integrating broader knowledge including Internet delivery technologies.

\section{Background and goals}

\subsection{Revision of previous geological maps with recent geological models}

The fundamental, essential parts in creating geological maps are field surveys and field observations. We conduct surveys at outcrops discontinuously exposed along rivers or in mountains to investigate types of rocks and formations and their structures. Developing geological models from observed data, we speculate on the rock distribution underground that are covered by soil and vegetation. How much information we can get from scant field observation and how precisely we can deduce the underground structure depend on the quality and quantity of geological knowledge and models we have. This "analog visualization" technique of extracting as much information as possible from limited field observations and deducing hidden structure beneath has been developed long before invention of computers.

Let us describe the case of Mino area in Gifu Prefecture as a typical example where the neighboring geological maps were drawn based on different geological models. There are four 1:50000 geological maps in this area: "Neo," "Hachiman," "Tanigumi," and "Mino" published in 1964, 1984, 1991 and 1995, respectively ${ }^{[4]-[7]}$. "Neo" was drawn according to the geosynclinals model $^{\text {Term } 1}$, which was predominant in geology before plate tectonics was accepted as a new geological paradigm in the 1990s. The geological division and expression adopted in this map are quite different compared to other maps, which were created based on the accretionary prism model $^{\text {Term } 2}$ formed by oceanic plate subduction. Furthermore, other three maps were made according to different geological models developed under the plate tectonics theory: submarine landslide ${ }^{\text {Term } 3}$ for "Hachiman," mud diapir ${ }^{\text {Term } 4}$ for "Tanigumi," and tectonic deformation ${ }^{\text {Term } 5}$ for "Mino." Consequently, geological divisions and expressions of the four maps are different (Figure 1).

As shown in the above example, knowledge of historical background and transition of theories may be necessary to effectively utilize geological maps. However, most users know little about past geologic concepts and theories even

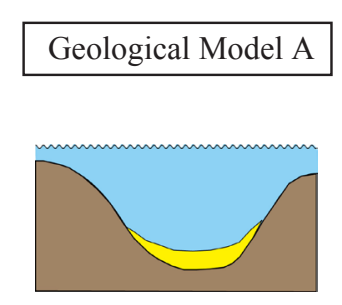

Geosyncline

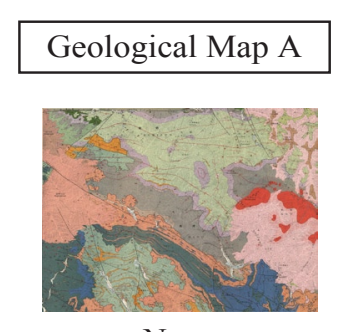

$\mathrm{Neo}$

1964

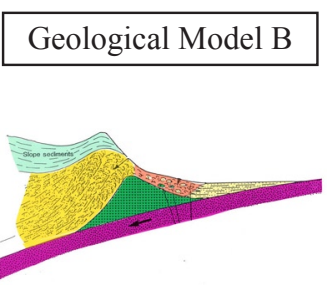

Submarine Sliding
Geological Model C

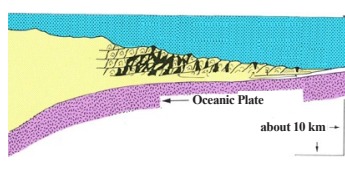

Mud diapirism

Geological Map C

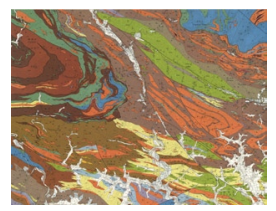

Tanigumi

\section{Geological Model D}

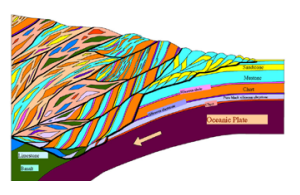

Tectonic deformation
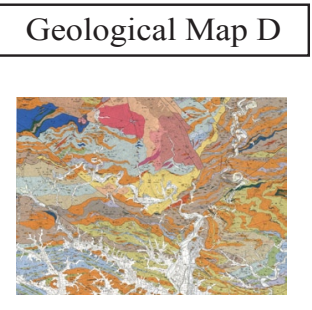

1991
Mino

1995

Fig. 1 Changes of hypothesis for formation of geologic bodies in Mino area, Gifu Prefecture. 
though they may be acquainted with recent researches. They often become confused by unfamiliar explanations and expressions in old maps. In order to remove this obstacle, we developed a method for seam-smoothing geological maps, and applied it to the 1:200,000 geological maps, because they almost completely covered the Japanese Archipelago, whereas the 1:50,000 maps were insufficient for the purpose.

\subsection{Goals and scenarios}

Nothing can make geological maps more valuable than their wide spread use in the society. We set our research goal as follows: to contribute to the safety of our society by integrating the geological maps that were created independently and by promoting the use of these maps through effective delivery.

The research scenario to achieve the above goal is as follows (Figure 2):

- Revision of each map drawn according to different geological models, recompilation with the latest integrated standards, and seam-smoothing with adjacent maps

- Delivery of harmonized maps on the Internet, rather than by print or CD-ROM media, to facilitate wide use in the society

- Standardization of the expression of geological information to allow interoperation with other ground information inside and outside Japan

\section{Procedures for harmonizing geological maps}

\subsection{Outline}

Harmonization of geological maps involves revision of old geological maps based on past models by applying up-to-date models.

The procedure includes unification of legends and adjustment

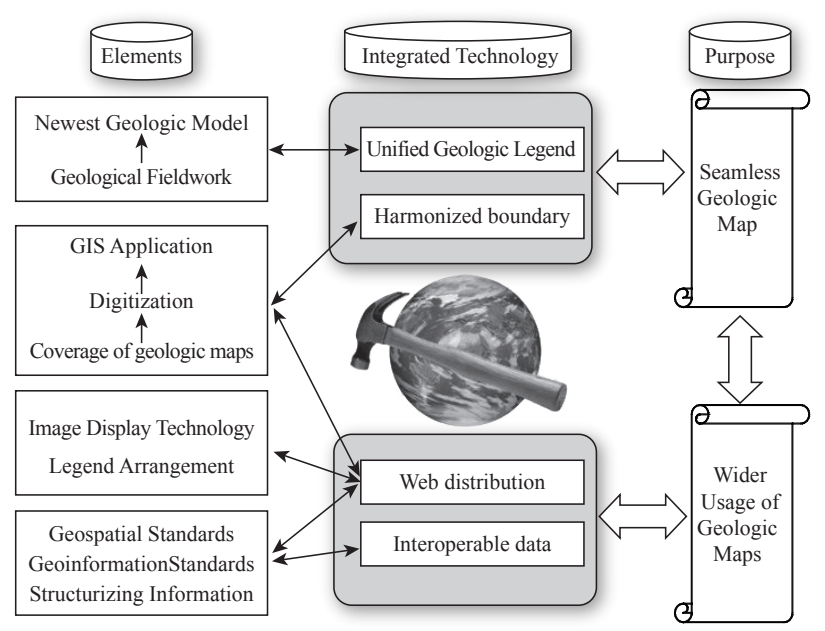

Fig. 2 Elemental technology and scenario for Japan Seamless Geological Map Project. of geological features such as boundaries and fault lines (Figure $3)$. In order to give priority to prompt distribution of the results, no extra field surveys were conducted in this project.

The 1:200,000 geological maps, of which 112 maps have already been published, cover about 90 percent of Japan (as of March 2006), and they are most detailed maps that could be harmonized. The revised seamless geological maps of Japan based on these maps are the most frequently used example of seamless geological map ${ }^{[8]}$.

Launched in 2002, the project published areal seamless maps in series as follows. In 2003, Hokkaido and Tohoku regions were completed, followed by the Kanto region in 2004, completing the eastern half of Japan. Three regions of Hokuriku, Tokai, and Kinki were completed sequentially in the same fiscal year. In 2005, Chugoku and Shikoku regions, Kyushu region, and Nansei Islands were completed, covering the western half of Japan. Adding several areas of southern Kanto region (Izu Northern Ogasawara, Izu Southern Ogasawara) and eastern area of Hokkaido (including four islands of the Kuril), as well as the revision of Hokkaido region, the first edition of the national seamless map was published. This digital geological map was drawn with unified legend and consisted of massive amount of data involving 149,081 polygons and 371,528 lines (as of May 12, $2007)^{[9]}$.

\subsection{Unified legend}

The first step in seam-smoothing geological maps was unification of the legend. As legend gives all description of geological features in the map, it was necessary to develop a common legend applicable to all neighboring maps under the latest geological model. However, limited amount of information in old geological maps makes it impossible to apply the latest legend to all maps. Most up-to-date yet most widely applicable legend was chosen based on recent geological model.

The unification was carried out in two stages, applying the existing legend system and applying it to the 1:200,000 maps.

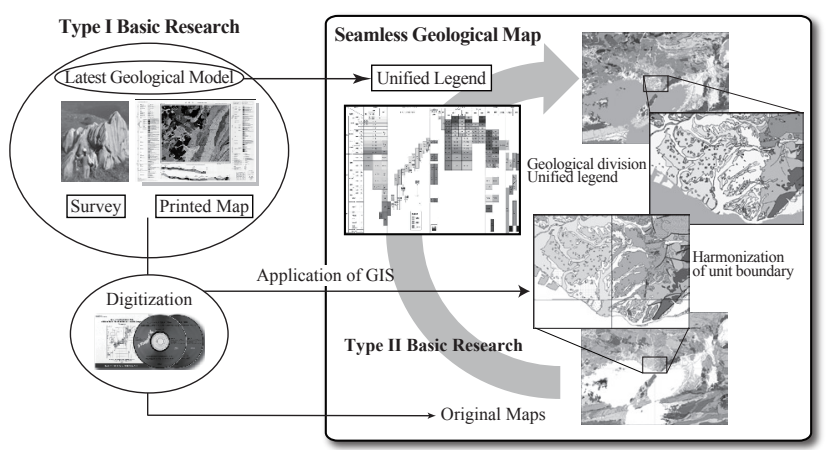

Fig. 3 Concept and process of Seamless Geological Map of Japan 1:200,000. 
Every geological map has unique geological divisions or local formation names to describe the geological information of the area. However, a common legend must be applicable to all formations and rocks in Japan. Consequently, only two criteria - lithology and age of rocks - were employed in the legend. Similar legend system had already been developed and adopted for the first time in the third edition of the $1: 1,000,000$ scale geological maps of Japan $(1992)^{[10]}$. It was the only nationwide legend created from the most precise geological model in 2004 when the project started. Applying this legend (basic version) as standard, we published the seamless 1:200,000 scale map on the web as the first stage. However, the legend for the 1:1,000,000 scale maps was too rough for the 1:200,000 scale maps to provide sufficient information, due to far greater quantity and quality of information in the latter. To solve this problem, improved unified legend with more detailed geological division was developed in the next stage (Figure 4).

A criterion for nationally consistent petrological and stratigraphical divisions for the larger scale map was reviewed and discussed in five categories (sedimentary rocks, accretionary prism, volcanic rocks, plutonic rocks, and metamorphic rocks). Metamorphic rocks were further classified into three categories: 1) metamorphic conditions, 2) age of metamorphic rocks, and 3) original lithofacies ${ }^{[11]}$. Accretionary prism was subdivided into two categories for rock types in each structural unit. Legend for sedimentary rocks was reviewed according to detailed subdivision of geological ages based mainly on regional stratigraphic correlation. Besides geological age, classification by chemical composition was carried out on volcanic and plutonic rocks. Holocene sediments in densely populated plain regions were subdivided by sedimentary environment including dune, wetland, alluvial fan, natural levee, lake, and artificially altered land.

Though the above classification was ideal up-to-date legend for the harmonized 1:200,000 maps, not all regional maps could adopt the above classification, as they were compiled during varying periods. Listing all the legends used in each map and comparing them with the ideal legend, 384 geological divisions were adopted as optimum combination for the new geological map. The number of divisions nearly doubled from 194 divisions in the 1:1,000,000 maps. The new legend allowed the seamless geological map to provide more detailed information. Figure 5 is an example of the map of Shikoku region.

\subsection{Application of unified legend and establishment of single attribute table}

After replacing the former legend with the new legend, reassembly of attribute data in digital geological maps was carried out with the aid of geographic information system $(\text { GIS })^{\text {Term } 6}$. Polychromatic analog maps were digitized, and original classification was given to each geological province, followed by permutation by correlating with the unified legend. Adopting vectors ${ }^{\text {Term }} 7$ to digitized geological data enabled independent calculation within each area as well as automatic slimmer, and resulted in both rapid data compilation and cost reduction, while maintaining the location accuracy of geological boundaries.

As stated above, correlation of each classification in original maps to the most recent maps was very complicated and specific task, because the geological models of the maps differed by time of their production. Compilation of geological maps required cooperation of several researchers specializing in different research fields such as volcanology and sedimentology, or formation of different geologic ages. They usually had their own fields of specialty in certain locality where they conduct research. Consequently, one or more geologists who were specialized in the region participated in the correlating procedure. For example, one geologist handled volcanic rocks in northern Kyushu while another worked on compiling sedimentary rocks in southern Tohoku region. Each specialist examined the old and new data, and correlated them with the aid of other references including relatively recent geological maps of neighboring areas or maps of different scales and the latest paleontological and/or radiometric data. More precise correlation was possible when sufficient data were available to make regional stratigraphic correlation tables and/or columnar sections. Some of the recent 1:200,000 maps were drawn with legend showing almost equivalent geologic ages to the basic version, and these allowed easier correlation.

\subsection{Boundary smoothing and compilation}

The next procedure was to maintain continuity of geological boundaries and fault lines between neighboring maps. This involved adjustment of precision and interpretations of the maps, by making old map data consistent with latest geological and topographic information (Figure 6). It also involved reviewing geological classifications and boundaries based on the latest geological model.

Combining neighboring maps is widely used procedure to create integrated geologic map. Wide-area geological map is usually made from larger scale maps. For example, the $1: 200,000$ geological map is made by combining 1:50,000 maps. However, no attempt has ever been done to create integrated map from original maps of the same scale. In compiling a smaller scale map from larger scale maps, one of the most common methods is reducing the large scale maps using a copy machine and joining the boundaries by hand. However, this is applicable only in cases where the accuracy of locality data may be sacrificed.

To create continuous geological map in same scale as the 


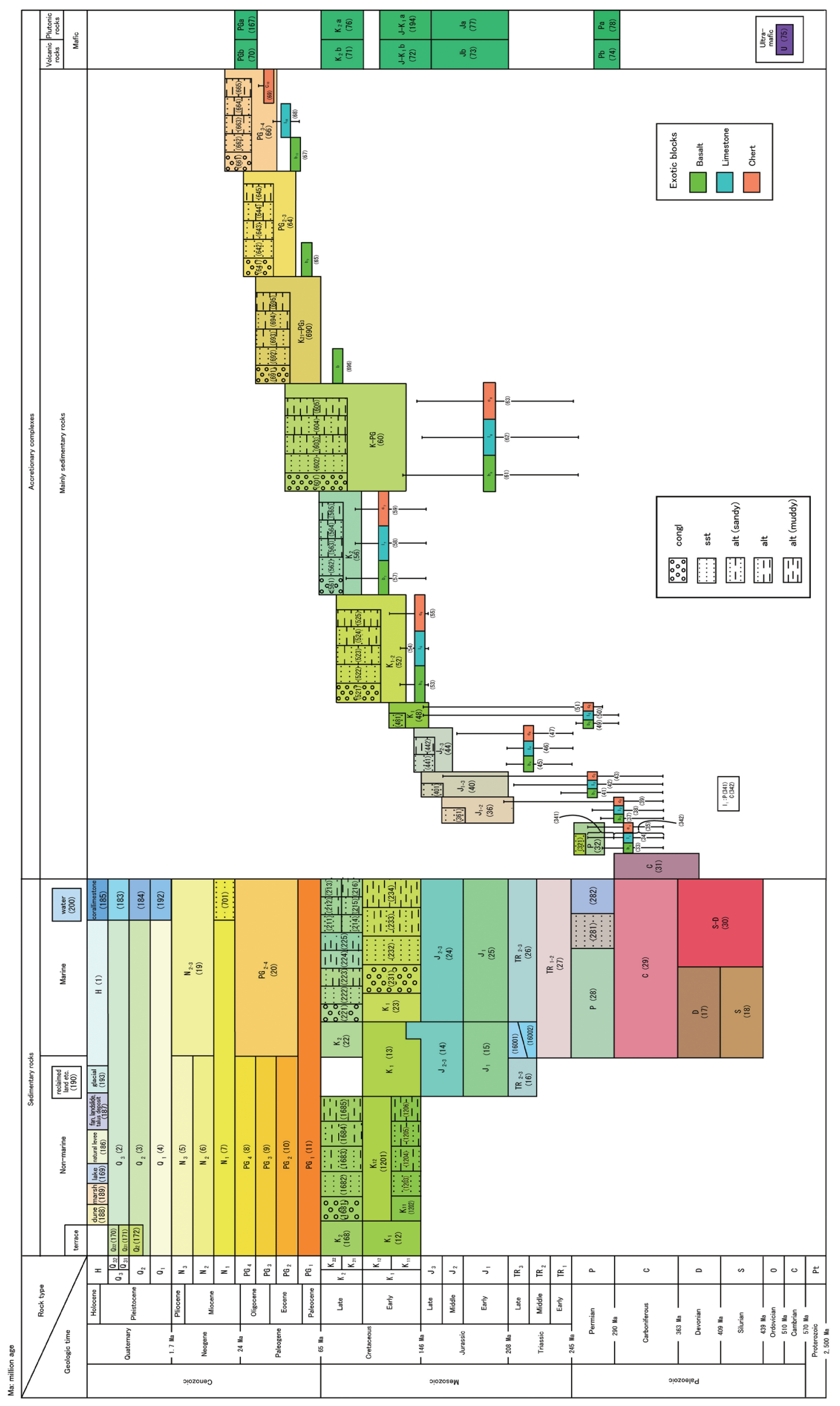

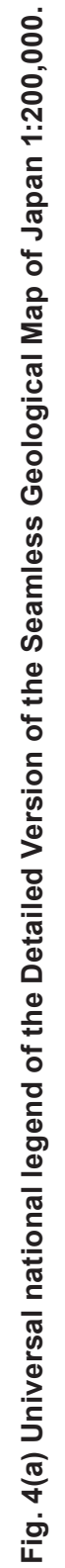




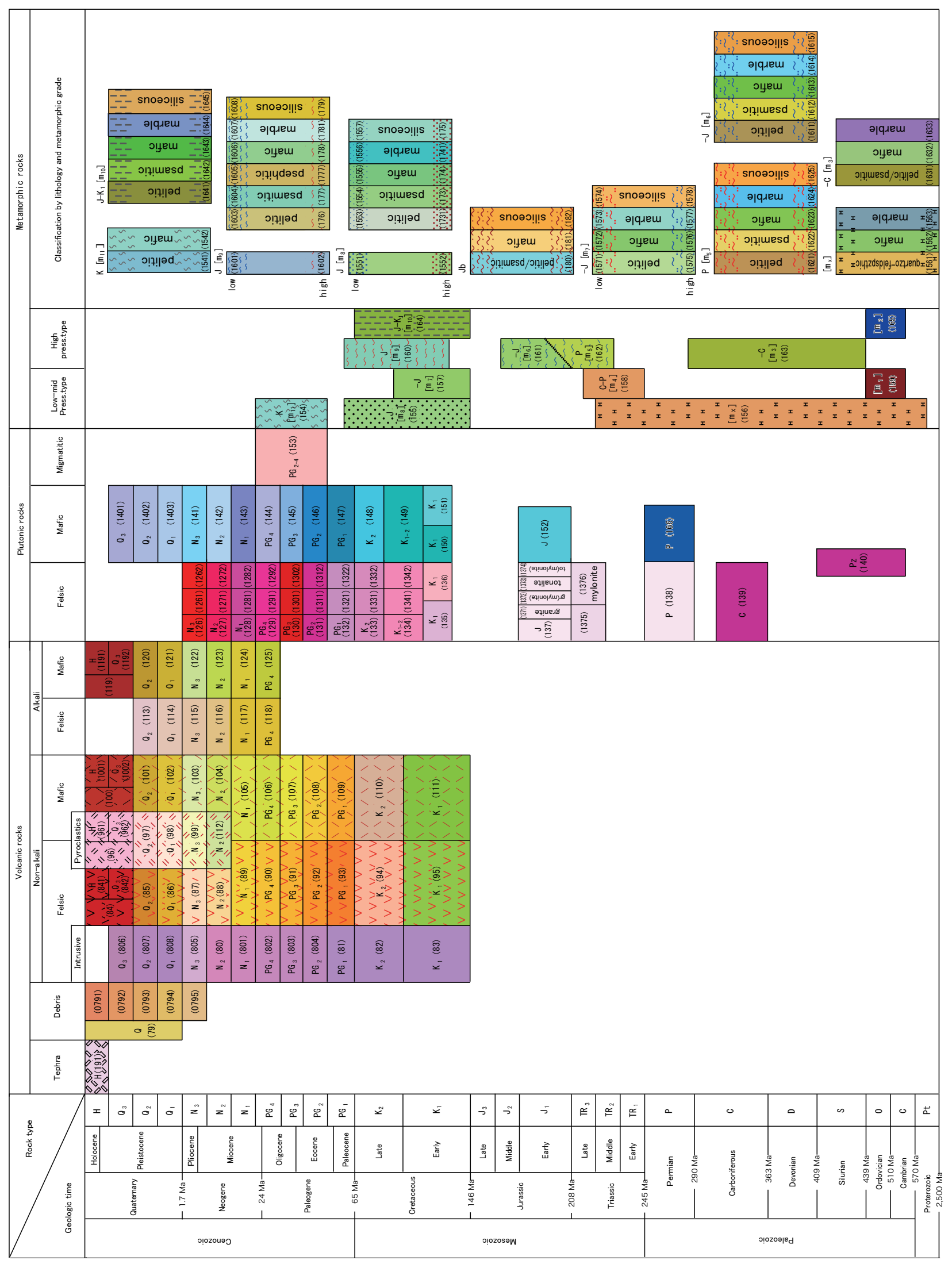

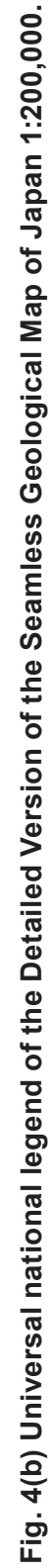


original maps, it is very important to maintain positional accuracy. Therefore, GIS was employed actively in digital geological map where possible. After the attributes in neighboring maps were replaced with the unified legend, the areas of same geological divisions in both maps should share the attributes. However, it often happened that single geological body seemed discontinuous or different, because the information were independently compiled and published in different times. In such case, extra procedure as described below was necessary to maintain continuity.

Generally, amount and accuracy of information in a map increase with time. In many cases, recent map contains more detailed and correct information of distribution of rocks or formations. In maintaining continuity of the boundary, the lines in old maps were altered to accommodate the lines in new maps. The latest geological information from the 1:50,000 geological maps or academic papers were employed to ensure better smoothing.

Since old geological map is drawn according to old topographic map, superposing an old geological map on latest topographic map often caused slight positional mismatch. In such case, position of terraces or alluvial fans was corrected so it would be consistent with the latest topological data. Coastlines often posed more difficulties. Positional adjustment of island coast was accomplished using affine transformation $^{\text {Term } 8}$, by establishing several benchmarks. In other cases, geological boundaries were extended or shortened to match older data to the present coastlines using GIS.

In addition to rock or formation boundaries, faults were reexamined to determine whether they were exposed or concealed based on latest research results. Specialists of the area and recent papers were consulted in making judgments on whether a geological boundary was a fault or not.

\section{From analog to digital, then from CD-ROM to the Internet}

\subsection{The significance of digital geological map}

Geological maps were generally printed on paper. Since

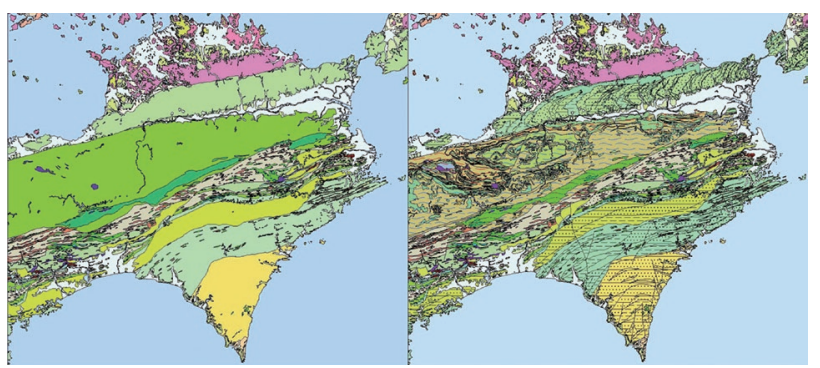

Fig. 5 Two types of the Seamless Geological Map of Japan 1:200,000.

Basic Legend Version (left) and Detailed Legend Version (right). the 1990s, with the development of GIS technology, social demand for digital geological maps increased. Therefore, we started to systematically examine the "publishing procedures by electronic media" in 1993, and published the first digital geological map on CD-ROMs in 1995. In contrast, seamless geological map has been distributed mainly on the Internet at present. The main reasons are: 1) it allows easier access to data and facilitates utilization, 2) it enables frequent data update, and 3) costless publication enables free (or low price) information provision.

In 2006, there were 600,000 accesses to the Seamless Geological Map of Japan published in 2002, while sales of other printed maps were only about 900 copies a year. Although it is difficult to directly compare printed maps that are used repeatedly, three-digit difference is substantial. Moreover, wide range of users such as consulting firms and real estate companies, as well as researchers have accessed our website (Figure 7).

\subsection{Distribution on the web}

In 2003, the National Institute of Advanced Industrial Science and Technology(AIST) started to offer seamless geological map on the web as one of research information database (RIODB, http://riodb02.ibase. aist.go.jp/db084/index.html). In the beginning, data were offered as images, although the original maps were created in vector format (Figure 8). Primary reason was because the public preferred to use maps in graphic form mainly to view and search and they were used to the printed version. Another reason was inadequate infrastructure for smooth browsing of vectorized data at that time.

The total size of the current 1:200,000 Seamless Geological

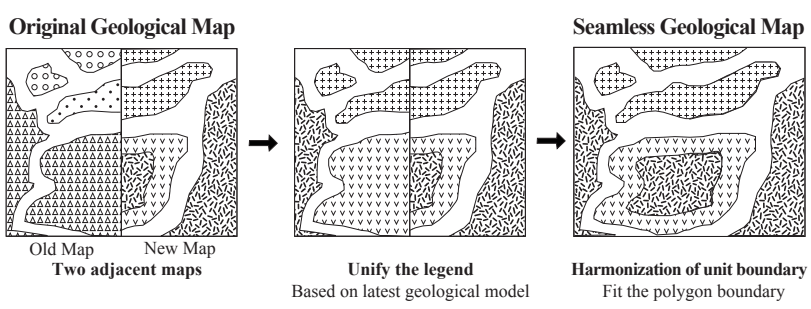

Fig. 6 Harmonization process for seamless geological map.
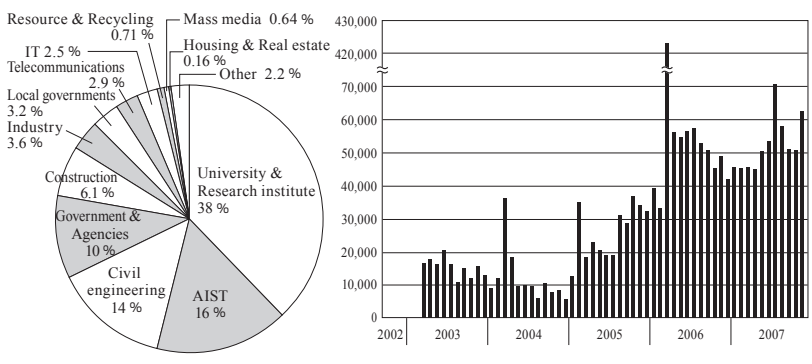

Fig. 7 User category (left side, reference to November 2007) and change of number of access to the homepage of Seamless Geological Map of Japan 1:200,000 (right side, from September 2002 to November 2007). 
Map of Japan provided on the web will be $3 \mathrm{~m} \times 7 \mathrm{~m}$ if printed in scale. Almost 4 gigabyte file size is necessary to provide image that is clear enough to be enlarged on screen (400 dpi). Since this data size is too large for users to download at once, it became crucial for us to develop a transmission system to instantaneously deliver required data to where they were needed. Although several software for this purpose were already available commercially, we decided to develop our own program, J-GeoView, to reduce cost and to optimize representational function. It enabled continuous zooming in/out and displayed geological explanation at the position of the cursor. Along with academic description, we provided plain and simple explanations without complex technical terms for general users.

\section{Further development of seamless geological map and challenges for the future}

\subsection{Refinement of geological information and integrating technology}

The seamless geological map was created without conducting field surveys. However, field surveys and mapping are essential to improve the accuracy of geological maps and to update the geological information such as distribution of rocks, faults, and other geological features. To accomplish this task, we must collaborate with specific research groups who are in charge of making geological maps at 1:200,000 and 1:50,000 scales. We are planning to revise the already published 1:200,000 geological maps in order of their publication date in the second business term of AIST (April $2005 \sim$ March 2010), and compile new maps in the third term or later (from April 2010). The above plans will significantly improve the contents of the seamless geological map.

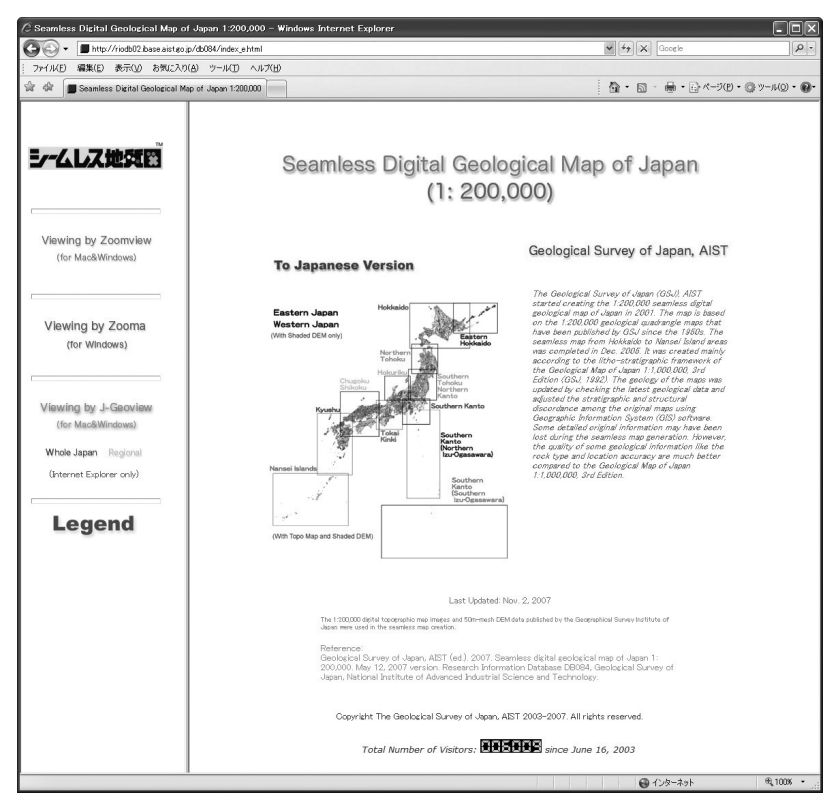

Fig. 8 Homepage of the Seamless Geological Map of Japan 1:200,000.
Data in the seamless geological map are delivered in vector format by GeoMapDB developed in 2006 at http://iggisl. muse.aist.go.jp/ja/top.htm. One of the features of vector format is that it can separately manage corresponding data by cutting each element that composes the ground surface based on object-oriented concept. It allows continuous zooming in/out and arbitrary change of color and size. It also enables addition of attributes for rocks or faults such as age, thickness, and lithofacies. The method adopted in seamsmoothing geological map fully exploits the above features. In the future, strict standardization of data and development of data model to standardize the structures among data sets will lead to deployment of the maps as spatial relational database, and consequently will result in convenient usage including flexible search, analysis, drawing, simulation, and automatic control $^{[12]}$.

Combination of these features will enable us not only to use the seamless map as a planimetric map, but also allows us to draw geological profile and multi-dimensional map, and create geologic time scale using a single set of data in the seamless geological map. We have started normalization and standardization of geological data, data model establishment, and development of the data to achieve these goals.

\subsection{Seamless geological map as an information infrastructure}

The seamless map aims not only for greater convenience and broader delivery via the Internet, but also aims to make geological maps shared and widely used in society as a common national property. We shall continue our efforts in making the map available to everyone through the Internet.

One example is the mutual use of data between engineering geological map and surface geological map of the Ministry of Land, Infrastructure, Transportation and Tourism (MLIT) and seamless geological map of the AIST, and this is making major contribution to the reciprocal exchange of the latest geological map information (Figure 9), as well as to cost reduction. Actually, engineering geological map ${ }^{[13]}$ was used as reference in the compilation of the seamless map of Shikoku region. On the other hand, vector data of the seamless geological map were used to create the engineering geological map of Tohoku region ${ }^{[14]}$. Interoperation between other geospatial information is another important aim of the seamless geological map. We are currently promoting joint researches in environmental field with Nagoya University, Tohoku University, and others. Within AIST, the seamless geological map is utilized as basic geological information in the study of active faults and soil contamination.

Creation of the 1:200,000 Seamless Geological Map of Japan triggered the research project called "Basic Research on Development of a Highly Information-Interoperable Database for Integrated Geoscience Atlas" in which other 
geoinformation will be improved and integrated at national scale. In this project, geophysical (gravity and aeromagnetic) and geochemical maps ${ }^{\text {Term } 9}$ are developed at 1:200,000 scale. They will be revised and published as a nationwide seamless geoscience atlas in set with seamless geological map. These maps are recognized as part of intellectual foundation of geoscience, and are expected to facilitate interoperation of information with other fields (Figure 9).

\subsection{International standardization and interoperation of geoinformation}

New system for "cloud computing" is necessary to mutually exchange and utilize geological map information on the $\mathrm{web}^{[15]}$. It is also required that any people and any system around the world share common understanding of definition of the terms. The Geography Markup Language $(\mathrm{GML})^{\mathrm{Term} 10}$ and its operational specifications WFS and $\mathrm{WMS}^{\text {Term } 11}$ are some examples of international standards for geospatial information proposed by the Open Geospatial Consortium, Inc. (OGC), the international organization for development of international standard for geospatial interoperability ${ }^{[16]}$. To become interoperable with other geospatial information of different fields and forms, the seamless geological map must conform to these international standards (Figure 9).

In order to realize interoperation among various geological information including geological maps, we joined the Commission for the Management and Application of Geoscience Information (CGI) under the International Union of Geological Sciences (IUGS) to discuss the development of GeoSciML, which is one of the international standards for geological information ${ }^{[17]}$. Similar to GML mentioned above, this is one of the XML vocabularies whose data model is described in terms of XML, and is compliant with GML for geospatial information ${ }^{[18]}$. We intend to provide interoperable geological data in the form of compatible parts, by splitting geological digital documents including digital maps into small pieces, and then embedding metadata using various

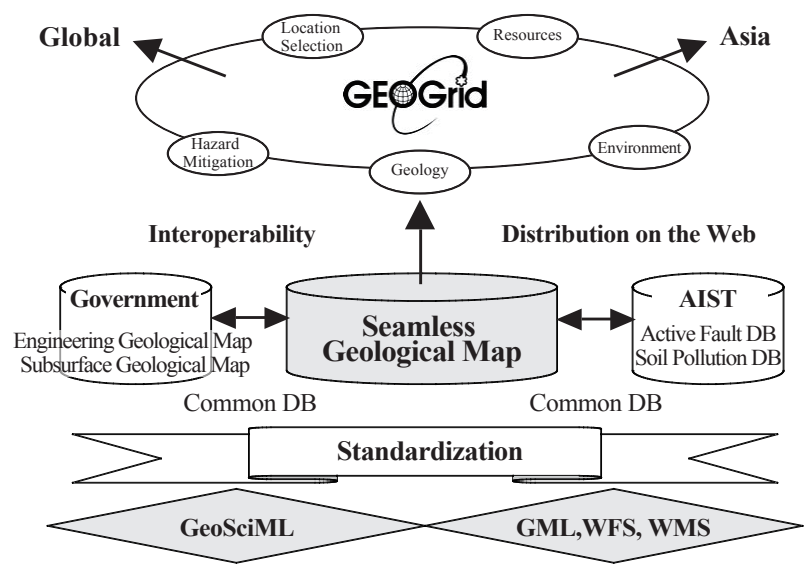

Fig. 9 Future model of Seamless Geological Map Project.
GeoSciML tags (Figure 10). Applying XML vocabulary including GeoSciML requires arrangement of data based on each data model. We also aim to rebuild the 1:200,000 seamless maps into spatial relational database by applying GeoSciML (Figure 10).

In utilizing geological information such as the seamless geological map, framework for secured utilization will be necessary in the future. The GEO Grid ${ }^{\text {Term 12 }}$, one of AIST's integrated issues, is an initiative that will allow this to be practicable (Figure 9). The GEO Grid project was started to study international data sharing among Asian countries as well as Japan. The seamless geological map has become one of major contents in the project, and it will enable interoperation among similar geological maps and related information in Asian countries (Figure 9). Natural resources and environment are borderless issues, and the geoinformation of surrounding countries are important for Japan to ensure stable economic development and secure society. Interoperation of geoinformation using the GEO Grid is expected to play an important role in the security of the society such as response to various disasters like earthquake and volcanic eruption in Asia.

\section{Conclusion}

We described the innovative methods of transforming traditional analog maps to the seamless geological map and the interoperation technology that allows the information to be used interoperably on the web.

Seamless geological map, which allows the public to use geological maps and information easily, can be regarded as an example of Type 2 Basic Research. The nationally harmonized 1:200,000 map was distributed over the Internet and accessed 600,000 times in 2006. The figure demonstrates wide utilization of the digital geological map. However, for broader dissemination of geological information to the

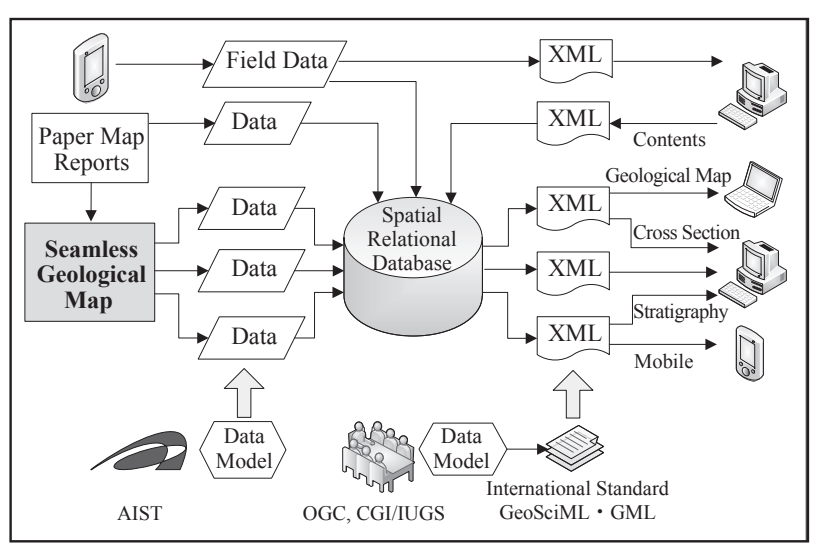

Fig. 10 Interoperable workflow based on the standardization of geoinformation. 
public, it is necessary to present finer geoinformation at larger scale. We started making seamless geological maps at scales of 1:50,000 to be utilized mainly in engineering and construction, and 1:25,000 to be used mainly for industrial and residential location survey. We ultimately aim to provide flexible services to general users by making these detailed contents accessible from cell phone or car navigation system. We shall continue to promote information and technology for safer society through our researches - creation of seamless geological maps and its interoperational technology - as Full Research of geoinformation.

\section{Acknowledgement}

We would like to thank the members of the Geological Mapping Group, as well as Mr. Jun-ichi Miyazaki and Dr. Joel C. Bandibas of the Geological Survey of Japan, AIST for their kind cooperation to our research.

\section{Terminology}

Term 1. Geosynclinal Model: An ancient geological model for hypothetical huge sedimentary basin. This was a major model for the origin of mountain building from late 1800 s to 1960 s.

Term 2. Accretionary Complex Model: A recent geological model for the origin of orogenic belts. The basic components of orogenic belts were derived from accretionary complexes that were caused by the interaction between subducting oceanic plate and continental margin. According to this model, the rocks that compose the foundation of Japan are composed of accretionary complexes.

Term 3. Submarine sliding origin: Major theory in the 1980s where submarine sliding caused fragmentation and mixing to form mélanges.

Term 4. Diapiric origin: A hypothesis to explain the ocean bottom around the Barbados Islands in Middle America, where extraordinary high pore fluid pressure caused mud diapirism to form mélanges.

Term 5. Tectonic origin: Theory that states tectonic shearing between subducting oceanic plate and overlying plate of the continental margin caused fragmentation and mixing to form mélanges.

Term 6. Geographic Information System (GIS): Any system for capturing, storing, analyzing, managing, and presenting data and associated attributes which are spatially referenced to earth. In narrow sense, it is an information system capable of integrating, storing, editing, analyzing, sharing, and displaying geographically referenced information.

Term 7. Vector format: Object-oriented data format that expresses spatial information consisting of polygon, line, and points. Spatial information is defined by location and attributes information.
Term 8. Affine transformation: A transformation method using linear transformation and parallel movements (eg. Euclidean geometry). Relationship between geometric lines is preserved after the transformation process.

Term 9. Geochemical map: Map showing distribution of 53 chemical elements based on the chemical analysis of about 3,000 samples from $10 \mathrm{~km}$ grids covering entire Japan.

Term 10.Geography Markup Language (GML): A standard for spatial and geographical data defined by the Open Geospatial Consortium based on XML.

Term 11.Web Feature Service (WFS) and Web Map Service (WMS): WFS is interface standard for geographical vector features, and WMS is spatially referenced information, defined by OGC.

Term 12.GEO Grid (Global Earth Observation Grid): A system to facilitate the integration of earth observation data and other spatial information using grid technology.

\section{References}

[1] S. Winchester (K. Nonaka, trans.): The Map Changed the World - William Smith and the birth of Modern Geology (Sekai wo Kaeta Chizu - William Smith to Chisitugaku no Tanjo), Hayakawa Publishing (2004) (in Japanese).

[2] K. Kodama, K. Isobe, and M. Isobe: Mikata tsukaikata chishitsuzu (How to Read and Use Geologic Map), Ohmsha (2004) (in Japanese).

[3] K. Wakita and M. Inoue (eds.): Jitsumuni yakudatsu chishitsuzu no chishiki (Knowledge of Geologic Map Useful in Actual Business), Ohmsha (2006) (in Japanese).

[4] M. Kawai: Geological Sheet Map" Neo," Scale 1:50,000, and Explanatory Text, Geological Survey of Japan (1964) (in Japanese with English abstract).

[5] K. Wakita: Geology of Hachiman District with Geological Sheet Map at Scale 1:50,000, Geological Survey of Japan (1984) (in Japanese with English abstract).

[6] K. Wakita: Geology of Tanigumi District with Geological Sheet Map at Scale 1:50,000, Geological Survey of Japan (1991) (in Japanese with English abstract).

[7] K. Wakita: Geology of Mino District with Geological Sheet Map at Scale 1:50,000, Geological Survey of Japan (1995) (in Japanese with English abstract).

[8] K. Wakita, T. Igawa, and S. Takarada: Seamless geological map of Japan, a new concept geological map of Japan, Chishitsu News, 620, 27-41 (2006) (in Japanese).

[9] Geological Survey of Japan, AIST (ed.): Seamless digital geological map of Japan 1: 200,000, May 12, 2007 version, Research Information Database DB084, Geological Survey of Japan, National Institute of Advanced Industrial Science and Technology (2007) (in Japanese).

[10] Geological Survey of Japan: Geological Map of Japan at Scale 1:1,000,000, ver. 3 (1992) (in Japanese).

[11] K. Miyazaki: Unified legend for metamorphic rocks in seamless geological map of Japan (prototype), Bulletin of Geological Survey of Japan, 54, 295-302 (2003) (in Japanese).

[12] Albert K.W. Yeung and G.B. Hall: Spatial Database Systems - Design, Implementation, and Project Management, 
Springer-Verlag (2007).

[13] Editorial Committee of Geology of Tohoku Region for Construction Engineers: Geology of Tohoku Region for Construction Engineers, Tohoku Construction Association (2006) (in Japanese).

[14] Editorial Committee of Engineering Geological Map of Shikoku: Engineering Geological Map of Shikoku, Japan, Institute of Construction Engineering (1998) (in Japanese).

[15] K. Wakita: Digitization and standardization of geological map - their recent international trend, Chishitsu News, 588, 40-54 (2003) (in Japanese).

[16] Z.R. Peng and C. Zhang: The roles of geography markup language (GML), scalable vector graphics (SVG), and web feature service (WFS) specifications in the development of Internet geographic information systems (GIS), Journal of Geographical Systems, 6, 95-116 (2004).

[17] S. J.D. Cox, E. Boisvert, B. Brodaric, T.R. Duffy, B.R. Johnson, J.L. Laxton, S.M. Richard, and B. Simons: GeoSciML: a standards-based encoding for transfer of geoscience information from IUGS/CGI, Proceedings, International Association for Mathematical Geology, XIth International Congress, Liege, S05-04 (2006).

[18] M. Sen and T.R. Duffy: GeoSciML: development of a generic Geoscience Markup Language, Computers \& Geosciences, 31, 1095-1103 (2005).

Received original manuscript December 25, 2007 Revisions received Februuary 22, 2008 Accepted Februuary 22, 2008

\section{Authors}

\section{Koji Wakita}

Director, Geological Information Center, Geological Survey of Japan, AIST. Has worked at GSJ-AIST since 1977. Graduated from Nagoya University, March 1977. Obtained $\mathrm{PhD}$ in Earth Science, Nagoya University in 1988. Mapping geologist for the 1:50,000 and 1:200,000 scale geological maps. Specializes in mélanges and accretionary complex. Leader of RIO-DB 084 "Seamless Geological Map of Japan, 1:200,000." Council member of Commission for the Management and Application of Geoscience Information.

\section{Toshie Igawa}

Studied geology specializing in sedimentology and paleontology at Kyushu University. Received Ph.D. in Science from Kyushu University in 2002. AIST Postdoctoral Research Fellow from 2003-2007. Works for Japan Industrial Technology Association as a temporary staff since 2007. Compiled the seamless geological map of Japan 1:200,000 and 1:50,000.

\section{Shinji Takarada}

Senior geologist of Geological Survey of Japan since 1991. Received PhD in Science from Hokkaido University in 1994. Specializes in volcanology, especially gravity flows. Compiled data for Hokkaido area and volcanic regions and constructed website for seamless geological map. Also developed the Integrated Geological Map Database (GeoMapDB) using WebGIS technology.

\section{Yuichiro Fusejima}

Senior geologist of Integrated Geoinformation Research Group, Institute of Geology and Geoinformation, Geological
Survey of Japan, AIST since 2007. Constructed the Active Fault Database of Japan based on relational data-model. Continues to work on interoperability among geoscience information systems.

\section{Discussions with reviewers}

\section{Feedback to Type 1 Basic Research \\ Question (Akira Ono)}

I highly appreciate this research as one of the most significant Type 2 Basic Researches. You integrated original geological maps of quadrangle areas (the result of Type 1 Basic Research) into nationwide seamless map.

Although this study is outside my field, it seems to me that each original geological map is a unique and distinctive product that reflects the interests and abilities of individual researcher, as well as being presentation of research result based on the latest model of the time. I suppose the meaning of this study is reevaluation of these unique researches under a common standard called the unified legend.

While the study was conducted as a Type 2 Basic Research that required several years to harmonize the original geological maps, is there any possibility that it will positively influence future Type 1 Basic Researches, such as in compiling original geological maps? I expect the creation of the seamless geological map will inspire unique and distinctive geological researches in the future.

\section{Answer (Koji Wakita)}

Smaller amount of geological information and less positional accuracy in the original maps may affect the content of the neighboring areas in the seamless map, because it is harmonized according to existing 1:200,000 geological maps. The seamless map, which is the result of a Type 2 Basic Research, indicates the direction of our future research: in which area we should promote further Type 1 Basic Research or what kind of researches we should undertake. Also, because the seamless map contains much more detailed regional geological information than the past maps, it helps us narrow down the issues and subjects of research.

\section{Past seam-smoothing \\ Question (Akira Ono)}

I think the smoothing technique had been applied in maintaining continuity and consistency of geological data between neighboring geological areas before digitization and web distribution of geological information became common. Are you saying that development of digitization techniques and wide usage of the Internet facilitated full-scale map smoothing? Answer (Koji Wakita)

Although combining and harmonizing same-scale maps have been attempted over the ages, but it was no more than "compilation" in which smaller scale map was recreated by combining larger scale maps. One of the greatest challenges of the study was to harmonize geological maps into same scale map.

\section{Comparison of this seam-smoothing method to Google Earth Question (Akira Ono)}

I imagine that one of the major obstacles in developing and launching Google Earth, which is now commonly used on the Internet, was how to smooth boundaries. Can you indicate any common and/or different points in smoothing images for this study and Google Earth?

\section{Answer (Yuichiro Fusejima)}

Smoothing really didn't matter in launching Google Earth. That is because the information in Google Earth consist mainly 
of satellite images and aerial photos, which are ground surface information collected in short range of time. Their spacetime distribution density and accuracy are much more uniform compared to geoinformation. Of course, there still exist some elements that must be harmonized (data matching) in satellite images and aerial photos, such as photographic equipments and weather conditions. However, the vast amount of information enables application of statistical approach to data matching, and the problems are being solved gradually. The purpose of our challenge in harmonizing geological maps is to improve limited underground information so we may utilize them conveniently as ground surface information.

\section{Research trend in other countries Question (Akira Ono)}

I think seamless geological maps are attracting attention abroad. What are the research trends in other countries? And what is the level of Japanese research in comparison?

\section{Answer (Koji Wakita)}

Opinion on harmonization is divided among Asia, Europe, and the United States. France is promoting harmonization not only at 1:200,000 scale but also at 1:50,000, while the UK advocates using original maps. Some of the Eastern European countries like Czech Republic and Asian countries like Korea are conducting harmonization at around 1:200,000 scale. However, there is essential difference in geology of Japan compared to these countries. Japanese geology is much more complicated and unique, because Japan is part of active island arcs. This geological condition requires us to develop unique models. Thick vegetation and soil layer hamper us from obtaining sufficient information. We must revise geological maps drastically as advances are made in research. We face these difficulties today. On the other hand, geological maps of Europe and the United States, where most of their lands sit on stable continental crust, are relatively simple, and do not necessitate major revisions with advancement of earth sciences. Their geological maps can be harmonized easily, or in many cases, simply combined without seam-smoothing. This doesn't mean our research level is inferior. In Japan, because of its unique geological situation, advancement in basic research directly affects the quality of geological maps. In my opinion, we cannot provide more detailed and more comprehensible geological information to the public unless we create seamless geological maps. Considering this unique geological condition, I believe our level of research for seamless geological maps is quite high compared to other countries.

\section{Researches on geological maps \\ Question (Eikichi Tsukuda)}

I completely agree with your opinion that the study shows new direction for Type 2 Basic Research. However, I see problems in the logic that you consider all past geological surveys as Type 1 Basic Research. I understand that geological survey consists of both researches, while geological maps are created mainly by Type 2 Basic Research. I don't think geological surveys are conducted only for the sake of scientific discovery. The past geological maps were made by amalgamating the results of Type 1 Basic Research, adding latest knowledge, and were individually optimized, but also went through the "valley of death."

It seems to me that you are overcoming the second "valley of death" by promoting the research of seamless geological map to conquer new obstacles in research. What is your opinion on this point?

\section{Answer (Koji Wakita)}

I completely agree with you that geological map research has both aspects of Type 1 and Type 2 Basic Research, as I described in the paper. However, I do not share your view that geological map research mainly focuses on Type 2 Basic Research. In my view of the present geological map project, current 1:50,000 scale maps are research reports, while 1:200,000 scale maps should be recognized as comprehensive thesis published when results are sufficiently accumulated. They reflect individual idea of the authors, so they may have quite different interpretations and descriptions on same formations or rocks, even if they were published around the same time. In case the researcher decided not to publish a geological map of an area, or couldn't get enough information to publish, the area is left unpublished, even if there is great social demand. Stratigraphic division units are also independently named by each researcher and are not unified. This is why I said we haven't made enough effort to increase social value of geological maps. In the study of geological maps, we don't even have a general methodology to create social values, which is the principle of Type 2 Basic Research. This is the main reason that motivated us in the research of seamless geological map.

Having discussed geological map study for years, we concluded that geological maps, especially the 1:50,000 scale, emphasize their feature as research results of field geology containing the latest outcomes of specialized academic fields. The basic stance of the study is to offer our product, the standardized technologies for field geological surveys, to the society by making the best maps with which scientists can conduct advanced researches in their respective fields.

I realize that we simplified the role of Type 1 Basic Research to highlight the significance of seamless geological map that has aspect of Type 2 Basic Research. However, we recognize that this is a realistic description of research, considering the fact that the role of geological maps have greatly changed today from the first map that was created in Meiji Era. 